\title{
Domestic Surveillance and the Troubled Families Programme: Understanding relationality and constraint in the homes of multiply disadvantaged families
}

\author{
Sue Bond-Taylor* \\ University of Lincoln
}

\begin{abstract}
Summary
This article explores the experiences of families within the Troubled Families Programme in responding to professional concerns about the condition and maintenance of the family home. Drawing upon care ethicists' development of relational autonomy perspectives, neoliberal assumptions about personal agency and responsibility are challenged, and the complexity of the constraints upon families highlighted. Within this framework, family interventions can be repositioned, not as an intrusive form of domestic surveillance levied at working class women, but as an opportunity to support families (and especially mothers) to overcome oppressive conditions which constrain their capacity to act.
\end{abstract}

Keywords: Troubled families, responsibilisation, relational autonomy, care ethics, gender.

\section{Introduction}

The Troubled Families Programme (TFP) has seen the national expansion of family intervention services which deploy a named key worker to work intensively with families facing multiple disadvantage. This article draws upon recent debates about the ways in which the key worker is implicated in the surveillance of the family in respect of property maintenance, domestic chores and cleanliness (e.g. Flint, 2012 and Crossley, 2015a). 'Troubled' families have been constructed via discourses of 'dirt' and 'disgust' (Lawler, 2005; Tyler, 2006), as lazy, incompetent and irresponsible, and the causes of behaviour are presented as individual dysfunction and poor lifestyle choices. The TFP has therefore been characterised by a responsibilisation agenda which seeks to activate the 'troubled' family, with the mother at its core, in achieving more socially acceptable lifestyles.

Boddy et al (2016: 277) have argued that the consequence of this responsibilisation agenda is to 'risk losing sight of the complex interconnected and dynamic realities of families' lives, and hence of their support needs'. Research is needed which engages with families' subjective experiences of individual and social 
p. 208. Domestic Surveillance and the Troubled Families Programme: Understanding relationality and constraint in the homes of multiply disadvantaged families

constraint within the context of interdependencies (Flint, 2012) and provides insights into the connections between poverty, family functioning and individual behaviour (Jack and Gill, 2013). This article therefore explores the lived experiences of families as they try to make their house a home in the face of poverty and exclusion, and considers their perceptions of how family services might aggravate or ameliorate their difficulties.

Through an analysis of interviews undertaken within a local 'troubled families' service (Bond-Taylor and Somerville, 2013), with parents and their key workers, I explore the contextual and relational constraints on families who are struggling to meet the standards demanded by their housing provider or other agencies. This reveals parents (particularly mothers) to be quite 'house proud', with their self-esteem contingent upon their perceived domestic competence and 'respectability' (Skeggs, 1997). Yet there exist numerous factors over which they have no control, which impact upon their capacity to maintain the condition of the property. Gendered family structures and material disadvantage play a pivotal role in shaping these.

Highlighting the situated and relational nature of families' apparent inaction in maintaining their home provides an important challenge to the depiction of disadvantaged families as 'trouble' and to neoliberal enforcement strategies based around individual responsibilisation and the imposition of sanctions for noncompliance. In response to Boddy et al's (2016) call for the development of adequately theorised approaches to family intervention which recognise the complexity and contextuality of family problems, this article proposes the value of care ethicists' conceptualisation of relational autonomy as a strategy for enabling a more effective understanding of the limits of responsibility within the complex contexts of families facing multiple disadvantages.

\section{Background}

In recent years, successive governments have demonstrated their commitment to delivering interventions targeted at families presenting multiple social problems (Valentine, 2016). Whilst the labels attached to those families have changed over time (anti-social families, families with complex needs, troubled families) the narratives around them and proposed solutions demonstrate remarkable historical continuities (Welshman, 2012). Family interventions can in particular be traced back to the Family Service Units (FSUs) established in the post-war period to address concerns about the 'problem family' through intensive family casework (Starkey, 2000; Parr, 2011b). Since the 1990s, we have seen a reinvigoration of interest in developing intensive, whole family interventions, delivered by a named key worker. New Labour developed Family Intervention Projects (FIPs) which echoed the FSU approach (Parr, 2011b), and under the Conservative-Liberal Democrat coalition, the FIP model informed the flagship Troubled Families Programme (TFP), now expanded in its second phase by the Conservative government.

Within the first phase of the TFP, families were identified as 'troubled' on the basis of four criteria: offences by under-18's or anti-social behaviour by any member of the household; under-18's not on a school roll or given permanent or multiple fixed term exclusions; adult on out-of-work benefits; and a local discretionary criteria causing high costs to the public purse (DCLG, 2012a). Two of these criteria have in effect led to a focus upon the conditions of the family home and property maintenance. Firstly, the criteria around anti-social behaviour, often related to reported concerns by housing providers about the failure to maintain the property, and the threat or use of anti-social behaviour sanctions, including eviction, were common indicators of the need for intervention. Secondly, a number of local authorities used the discretionary criteria to 
p. 209. Domestic Surveillance and the Troubled Families Programme: Understanding relationality and constraint in the homes of multiply disadvantaged families

address child neglect and children on the edge of care. These concerns were frequently connected to issues around the state of the home in so far as it impacted upon the safety and well-being of the children. It is therefore important to bear in mind that for some families supported by the TFP, there were serious and pressing concerns, which required an element of crisis management, addressing the potentially very poor living conditions of the family, that may not seem out of place alongside the descriptions of 'squalor' given by Family Service Unit workers in the 1940s (Starkey, 2000). For these reasons then, the model is one in which "the help provided is often very practical and involves workers and families 'rolling up their sleeves' and 'donning the marigolds' working alongside families, showing them how to clear up and make their homes fit to live in" (DCLG, 2012b: 21)

However, in the longer term, the emphasis on the maintenance of the home relates to broader concerns about parenting practice and self-regulation through temporal routines, as the Working with Troubled Families report describes:

Workers help provide a routine for those living in chaotic circumstances, showing parents how to get children up and fed in the morning, how to prepare meals and how to put children to bed. Families' day-to-day skills such as cooking, hygiene and daily routines may often have been taken for granted by other agencies and they may need to learn these things for the first time. (DCLG, 2012b: 21)

A number of authors have identified the neoliberal ideologies which underpin family intervention services and the TFP in particular (Garrett, 2009; Crossley, 2015b; Tew, 2013; Bond-Taylor, forthcoming). Emphasising the market as the core mechanism for social organisation, neoliberalism discourages state dependency and limits social spending and public provision. Claims that so called 'troubled families' pose significant cost to the state are therefore used to justify interventions which promote family resilience, self-sufficiency and self-regulation so as to reduce this financial burden, and repay in the longer term the initial spending on family interventions. The TFP is thus underpinned by a responsibilisation agenda, which seeks to hold families to account for their 'troubles' and emphasises personal choice and agency (Bond-Taylor, 2014). Responsibility is transferred back to the individual, such that "human life is viewed as the sum of an individual's own "choices" for which he or she will be responsible' (Tronto, 2013: 40). Material disadvantage and social exclusion are therefore reinterpreted as the consequences of poor lifestyle choices or 'anti-social' values, and a new discourse of 'austerity parenting' has emerged, characterised by thrift and frugality in the face of welfare cuts and the responsibilisation of parents (usually mothers) for the moral behaviour of their children and preparation for their participation in the workforce (De Benedictus, 2012).

This has had a notably gendered impact, with a 'marked silence' (Nixon and Hunter, 2009: 119) in policy discourses on the disproportionate surveillance of households headed by lone women. Discourses of parental responsibility obfuscate the reality that mothers rather than fathers tend to be held responsible for their children's conduct and welfare (Nixon and Hunter, 2009; Parr, 2011a; Ashe, 2014). The relationship between family intervention services and housing providers in addressing 'anti-social' behaviour has particular implications for personal privacy and the right to family life (Brown, 2004). Garrett's (2007) critique of FIPs highlights the degree of coercion and control imposed upon families, and the intrusion into private life around issues of housework, personal hygiene, use of alcohol and daily routine. These critiques are framed by notions of panoptic power and governmentality (Flint, 2012) creating circumstances in which families are vulnerable to coercion and to infringements of their rights. 
p. 210. Domestic Surveillance and the Troubled Families Programme: Understanding relationality and constraint in the homes of multiply disadvantaged families

Crossley (2015a) has echoed Garrett's concerns about FIPs in his critique of the TFP, describing the focus on 'dirt' as symbolic of the historic tendency to depict the most marginalised working class families as unclean and hence immoral (see for example Skeggs, 1997; Macnicol, 1987; Starkey, 2000). He highlights the impact of the imagery of dirt and domestic functioning within the TFP, in which family workers are described as 'donning the marigolds' and 'getting down and cleaning the floors' (Casey, 2012, cited in Crossley, 2015a). Crossley's interest is in the 'work that dirt does' in functioning as a 'signifier of difference' (ibid) with the focus upon domestic conditions within the TFP facilitating the construction of othering discourses which focus on individual pathologies rather than socio-economic conditions. Accounts of the Family Service Units, similarly suggest that the narrative of the post-war 'problem family' was constructed around perceived low standards of housework, hygiene and child care, attributed to a focus on the personal failure or deficiency of the mother who needed to be retrained, rather than the high levels of deprivation experienced by some families at that time (Starkey, 2000; Parr, 2011b). This reflects Lawler's (2005) accounts of representations of working-class people (their houses, clothes, bodies) as marked by disapproval or disdain, held as markers of individual failings, such as ignorance, brutality and tastelessness. Such representations contribute to the long held imagery around disadvantaged families as having different standards to the rest of society, as George Orwell put it in his 1937 classic The Road to Wigan Pier, that 'middle-class people believe that the working class are dirty...and, what is worse, that they are somehow inherently dirty' (Orwell, 1989: 122).

In Mary Douglas' (1966) classic exposition of dirt as symbolic of disorder, she argues that, 'In chasing dirt, in papering, decorating, tidying we are positively reordering our environment, making it conform to an idea' (Douglas, 1966: 2). In doing so, we mobilise notions of respectability and distinguish ourselves from the 'Other' whose 'dirt' symbolises their disorder (Warner, 2015). Tackling 'dirt' in that respect symbolises attempts to distance oneself from a less civilised, untamed state of nature, since 'unclean houses symbolise the inner chaos of people's lives through their lack of interest in having a home and caring about it' (Saugeres, 2000: 595). 'Dirt' is therefore perceived as an indication of levels of 'risk' to which Children's Services must respond in order to provide effective protection for vulnerable children living in dangerous or inadequate conditions. The penetration of the home has consequently become increasingly important in social work practice with disadvantaged families (Warner, 2015) and 'troubled families' interventions which aim to address child protection concerns are therefore also inevitably concerned with domestic surveillance.

The responsibilising focus of 'troubled' family intervention services upon the condition of the family home, in order to address concerns expressed by housing providers and child protection teams, risks reinforcing stigmatising depictions of families as pursuing anti-social, disorderly and 'dirty' lifestyles because of an inherent 'otherness'. This framing of the problem legitimises the focus of state intervention on the domestic activities of working class women (Parr, 2011a) and thus reinforces gendered and classed divisions of domestic labour. However, critics who reject such interventions on the grounds that they enforce middle class domestic standards upon working class families risk playing into such othering discourses, by assuming that working class families have different standards and want different things for their family home. Rather, research must consider the complex interplay between agency and structure, between what families want and what they are capable of achieving, and how personal 'choice' and autonomy play out in the relational contexts of multiple disadvantage and family interventions support.

Moreover, some services explicitly work to refute 'othering' discourses (Tew, 2013) and generate "more complex interactions" (Flint, 2012: 825) between families and 
p. 211. Domestic Surveillance and the Troubled Families Programme: Understanding relationality and constraint in the homes of multiply disadvantaged families

project workers which are not wholly disciplinary, promoting agency and empowerment (Bond-Taylor, 2015). More positive evaluations of the family interventions model therefore identify their potential to generate innovative and creative approaches to intervention which connect both emotional and practical support (Parr, 2011b; Hayden and Jenkins, 2014) in ways which families (and especially mothers) appreciate (Parr, 2011a; Morris, 2012; Bond-Taylor, 2015).

\section{Theories of relational autonomy}

The relational ontology of the ethics of care focuses on the ways in which human beings are inherently interconnected through the universal experiences of giving and receiving care across the life course (Gilligan, 1982), situated within 'nested dependencies' (Kittay, 1999: 132). Care ethicists argue that within neoliberal political discourses this reality of human interdependency has been denied through the assumption of individual autonomy (Fine and Glendinning, 2005; Tronto, 2013). Mackenzie and Stoljar (2000) have described how the concept of autonomy has become conflated with a limited conceptualisation of it, characterised by the selfsufficient, individualist, rational actor of libertarian 'justice' theory (Mackenzie and Stoljar, 2000). This caricature has been critiqued by care ethicists for failing to take into account the interconnectedness between human beings and the social contexts within which 'choice' is exercised, thereby promoting an 'autonomy myth' (Barnes, 2012). Care ethicists have consequently attempted to 'reclaim and reconceptualise' autonomy in a relational sense (Mackenzie and Stoljar, 2000: 5) in ways which involve "explicit recognition of the fact that autonomy is both defined and pursued in a social context and that social context significantly influences the opportunities an agent has to develop or express autonomy skills' (McLeod and Sherwin, 2000: 259-260). Human autonomy is therefore understood as an achievement which takes many years to reach, dependent upon relational and social structures (Tronto, 2013).

Considering the relational contexts of autonomy is particularly valuable in unpicking responsibilisation agendas aimed at oppressed and marginalised social groups where the focus on freedom of choice overlooks the lack of choice experienced by those living in conditions of vulnerability and dependence (Baier, 1987). Tronto argues that notions of personal 'choice' and responsibility have an ideological function 'when the expectations for responsibilities have been fixed along lines that reflect inequality and historic forms of exclusion' (Tronto, 2013: 42). The autonomy myth has therefore been politically expedient in allowing policy makers within neoliberal governments to seek to promote individual rather than collective responsibility for well-being (Barnes, 2012). The concept of relational autonomy was developed by feminist theorists as a response to the challenges in explaining impairment of autonomy in the context of conditions of oppressive socialisation. It allows us to move from narrow procedural accounts of autonomy, concerned only with the processes of decision making, to more substantive accounts which integrate normative considerations, acknowledging that decisions that appear prima facie to be the result of autonomous choices can still violate autonomy (Tronto, 2013), as Christman describes:

Those who are acting voluntarily and rationally (in a narrow sense) but on the basis of values that they have been forced or manipulated into adopting, or which arise out of pathological, oppressive, or overly constraining conditions are not acting as self-governing agents. (Christman, 2014: 373-374) 
p. 212. Domestic Surveillance and the Troubled Families Programme: Understanding relationality and constraint in the homes of multiply disadvantaged families

Discussion of oppression can therefore include harmful interpersonal relationships which interrupt the autonomy of the individual, but also wider social conditions which affect whole social groups (McLeod and Sherwin, 2000). McLeod and Sherwin (2000) describe four ways in which oppressive socialisation and interpersonal relationships impede an individual's capacity for autonomous action:

1. By limiting the options which are reasonable for an agent to choose.

2. By shaping an agent's values and desires in ways that undermine capacity for autonomous choice, e.g. by pursuing internalised oppressive social norms.

3. By depriving individuals of the opportunities and environment for the development of autonomy skills.

4. By promoting the internalisation of a sense of social worthlessness and incompetence that translates into lack of self-worth and self-trust.

Mackenzie (2000) rejects autonomy as a process of rationalising decisions, emphasising instead the role of imagination, as we rehearse the practical and emotional outcomes of our decisions. Oppression acts to restrict our 'imaginative repertoires' - our capacity for 'imagining oneself otherwise' (Mackenzie, 2000: 124). In particular, trauma and psychological violence deprive people of their ability to reflectively determine a life plan that they can take ownership of (Christman, 2014) and consequently 'expectations about the reliability of the world and of one's capacity to achieve any of one's goals can be destroyed (Halpern, 2001: 112, cited in Christman, 2014: 379). Furthermore, MacKenzie and Stoljar (2000) draw attention to an important distinction between decisional and executional autonomy, thus an agent may be capable of making decisions but may not have the ability to operationalise, implement or carry them out (Fine and Glendinning, 2005). Tronto (2013) notes that this is connected to questions of power and resources, since even if we accept that someone is capable of autonomous decision making, under conditions of oppression and given the existence of social and economic inequalities, individuals may not possess sufficient control over their lives or the necessary resources to act upon their decisions.

Questions of autonomy, relationality and interdependency have clear relevance for any assessment of the discourses and practices within 'troubled' family interventions which seek to promote independence, self-sufficiency and responsibility for the problems which families experience. Conditions of inequality or oppression which threaten the substantive exercise of autonomy impose limits on the degree to which an individual can be held responsible for their apparently 'autonomous' decisions.

\section{Methods}

This paper details the problems faced by families targeted for support by family intervention services and the practices involved in delivering family interventions, drawn from the experiences of the key workers and the parents themselves. These experiences are derived from interview data collected in the course of a programme evaluation research project conducted by the University of Lincoln on behalf of a local authority to evaluate the success of their Community Budget Pilot for supporting families with complex needs. After the pilot period, the service continued to operate as the core mechanism within the local authority provision for the delivery of the TFP. The local authority serves a largely rural area peppered with smaller urban pockets, mostly in the form of market towns and seaside resorts. All fourteen key workers employed by the service at that time were interviewed along with their two line managers, focusing 
p. 213. Domestic Surveillance and the Troubled Families Programme: Understanding relationality and constraint in the homes of multiply disadvantaged families

on aspects of the key worker's role and their work with specific families. A second round of interviews was later undertaken to explore the development of the project and the progress made by families, with eight key workers and one line manager available for re-interview. All of the key workers and their line managers were female (although male key workers had previously been employed).

A sample of 14 families were identified by the research team for possible interview, one from each key worker's caseload, covering a range of family structures and problems. Keyworkers acted as gatekeepers, giving advice about vulnerabilities and risk of harm. Two families were identified by the service as posing high risk of physical harm (to themselves or the researchers) and suffering high levels of distress about their situation, and consequently were not included in the sample (echoing Morris's 2012 experiences of negotiating access to families and responding to staff concerns). Three of the families selected were unwilling to take part, and a further family chose to withdraw from the service. Where inclusion of our first choice of family was not possible, the key worker was asked to identify an alternative family from her caseload who were willing to speak to us, and we were able to include a further four families in this way. Therefore, in total, twelve families were included in the sample, nine of which also provided a follow up interview at a later date. This approach to sampling may have impacted upon the characteristics of the sample by excluding the most complex families, the most difficult or most resistant to support, and consequently may have limited the variety of perspectives obtained from families. However, in line with the feminist ethical tradition which "emphasises care and responsibility over outcomes" (Parr, 2015c: 198) the need to maintain ethical standards and protect vulnerable individuals was prioritised over the representativeness of the sample.

The research set out to interview whole family groups, however this was difficult in practice, due to the fragmented nature of the families, older children's tendency to be elsewhere, and younger children's unwillingness or unsuitability for taking part. Only two fathers and five children took part in the interviews, and mothers' voices clearly dominated the research. A further two children provided additional research data through a questionnaire, and one child contributed an arts-based visual representation. In addition to the interviews, the families' assessment and planning documents provided wider information about their problems. The poor condition of the home was frequently identified in the plans as an area in need of immediate action in response to an escalating risk of eviction or child protection proceedings. Some interviews took place in the family home, providing an opportunity for observations to also inform the research, for example in better understanding the families' living conditions and local environment.

\section{Maintaining the home}

In all of the families interviewed, considerable work had been done within their home to improve the living conditions, including cleaning, clearing clutter, decorating, and replacing furniture and white goods. Whilst there was some variation in the key workers' approaches, they all agreed that there are minimum standards which require urgent action to address because they fail to meet basic health and safety standards, posing a risk to the family's wellbeing. This related to levels of cleanliness, especially in the kitchen, concern about hazardous items left around the home, such as knives or electrical cables, and the provision of basic furniture.

The condition of the children's bedrooms was a concern frequently identified by the key workers, which needed urgent attention upon referral as a number of the children had no bedroom furniture when they started the project, and therefore nowhere to 
p. 214. Domestic Surveillance and the Troubled Families Programme: Understanding relationality and constraint in the homes of multiply disadvantaged families

sleep or put away clothes. The key workers' descriptions of the conditions in which they found children were trying to sleep provide a powerful image which demonstrates the degree of disadvantage experienced, and illuminates the behaviour of some of the young people, in relation to offending, school disruption and truancy:

[Son's] room was that bad filled with clutter, just hoarded toys, rubbish on the floor. It wasn't hygienic, there was flies and there was cats so it was pretty bad, and he was sleeping on a very dirty mattress with a blanket which was dirty. (Key Worker H)

I couldn't believe the state of the children's bedding. I've never seen anything so filthy in my life; really, really filthy. The beds were broken in half. It was just - I don't know how they slept there. (Key Worker N)

The children have been sleeping with Mum in her bed because that's the only room that has got a carpet - their rooms haven't got carpets or anything like that So we are going to look at getting some flooring down to get the children back in their own rooms so they can have a regular routine and get into a good night-time routine, really, because they're not sleeping well at all, sharing a bed with Mum, and it's not ideal at all - not for a 10-year-old male. (Key Worker F)

Once these basic living conditions were addressed, key workers turned their attention to cleaning and tidying regimes, and it is here that questions about the surveillance of families might be raised. One key worker describes, 'the boys' room is absolutely appalling. They just lob everything all over the floor, the rubbish, if they have a bag of crisps chuck it on the floor, dirty clothes on the floor' (Key Worker B) whilst another noted 'the boy's got antisocial behaviour and he's just leaving rubbish in the home and not cleaning his room' (Key Worker $\mathrm{H}$ ). Many teenagers have messy bedrooms, yet in these families it is identified as a form of anti-social behaviour which is a problematic label for families in rented social housing. One key worker talked about getting teenagers to agree to aspects of the family plan, including that their 'bedroom must be tidied every single day' (Key Worker D), with the mother expected to police this tidiness on a daily basis too. Not only does this appear unrealistic, it also demands levels of tidiness unlikely to be followed in most households, with or without teenagers.

Whilst some key workers did appear to have very rigorous expectations of cleanliness and asked families to follow cleaning rotas and regimes, by contrast, other key workers appeared to resist the strict levels of cleanliness expected of families by social workers and housing officers, and support families to challenge these expectations and agree more reasonable standards, as this key worker describes:

...so then [social workers] say, "Oh, the floor wasn't mopped". I'm sorry, the floor in my house isn't mopped either. (Key Worker G)

Which do they leave? They get criticised if they leave the pots in the sink if they sit and play with their children and then they get criticised if they do the washingup and don't sit and play with their children, you know, round and round this roundabout we go... (Key Worker $\mathrm{G}$ )

This latter key worker account echoes the tensions evident in the historical development of child care advice which has seen a shift in emphasis from prioritising merely the physical health and hygiene of the child, to their emotional well-being and development (Starkey, 2000). Different services, and indeed individuals within services, may have different interpretations of how these two things must be balanced. 
p. 215. Domestic Surveillance and the Troubled Families Programme: Understanding relationality and constraint in the homes of multiply disadvantaged families

For example, whilst housing officers may prefer parental time to be spent maintaining their property, child psychologists may expect parents to spend more time actively engaged with their young children. Key workers therefore play an important role in navigating and managing these expectations on behalf of families.

Contrary to the popular images of feral families whose lack of domestic standards reflect laziness and an affinity for 'dirt' (Crossley, 2015a; Lawler, 2005; Warner, 2015), most of the parents interviewed noted their own desire to maintain a pleasant home, with one mother explicitly describing herself as house proud and others doing so implicitly. So-called 'troubled families' are therefore not immune to the pressures to maintain domestic standards, but rather feel they are fighting a losing battle against constant atrophy or decay. Mothers in particular connected the state of the family home to their own self-esteem, and mental well-being. They felt bad when the house was in a state of disorder as it reflected their lack of control over their lives, and they had strong visions of what they would like their home to look like:

They're going to help me decorate as well because my house is getting me down because it's been like this ever since I moved in and it's getting a bit... as you can see... (Mum, Family 24)

Conceptualisations of relational autonomy help us to avoid a simplistic focus upon 'choice' and human agency which might be generated by neoliberal responsibilisation projects, and to consider more contextualised understandings of the complex and interconnected constraints experienced by families living with poor housing conditions, and the ways in which personal agency is played out in those contexts. A number of obstacles were evident in the interviews as having made it difficult for families to match aspiration with action, and prevented the parents from acting autonomously to achieve the desired domestic standards.

\section{Health concerns}

Firstly, families experienced physical health conditions which provided challenges for the individual with the condition, but also impacted upon the daily lives of all family members and made it difficult for them to maintain the home. In one family headed by a single father in ill health, a sudden hospital admission left the children to fend for themselves. In another family, the lone female parent struggled to undergo cancer treatment and effectively manage a chaotic household:

And, bless her, I mean Mum's got cancer, she's been ill since last summer, so the kids have kind of run riot for want of a better expression since then. They've got no respect for any of the property or the belongings or anything, so the house is trashed. (Key Worker A)

This story was echoed in a number of households where parents struggled to contain their children's violent and destructive behaviour, as this father told us about his daughter, before she received mental health support:

She used to fight. She even through chairs and everything at me. She even smashed my windows and smashed my telly. (Dad, Family 48)

Mental health conditions seemed to be even more prevalent than physical complaints, and certainly more debilitating for families. Some mothers talked about their experiences of depressive illness, eating disorders, substance misuse (including alcohol, street and prescription drugs) and more widely, lack of confidence and very low 
p. 216. Domestic Surveillance and the Troubled Families Programme: Understanding relationality and constraint in the homes of multiply disadvantaged families

self-esteem. This was extremely debilitating and affected levels of motivation and capacity to maintain the home effectively:

Through my depression I let the house go and the kids go and that, so it's all starting to build back up again. (Mum, Family 2)

Mother, alcohol-dependent, not as much now but, you know, because of that long period of time, she's got two teenage sons, the house is just horrendous, she's, you know, not cared. (Key Worker E)

Children whose parents were affected in this way therefore took on additional caring responsibilities, tasks and chores within the household. Where children did not adopt this role, the condition of the property could quickly deteriorate. For both generations, the connections between mental health problems, substance misuse and domestic violence were evident, although the direction of causation is complex and varied. Families where both parent and child suffered mental ill health faced particularly challenging circumstances, making it especially difficult to maintain the condition of the property and make it a home.

\section{Unsuitable housing}

A second common theme was that of unsuitable housing and overcrowding. One family had a teenage brother and sister sharing a room, which they felt wasn't too detrimental since previously six family members had shared that two bedroom property. Another mum was so determined not to allow her two children to share a room in their two bedroom house that she slept on the sofa. Living in overcrowded housing adds pressure on relationships and makes it extremely difficult to keep a tidy and organised home due to inadequate storage.

...it was overcrowding in a tiny house, lots of children. It was chaos. The boys were sharing a box room and these two boys have got learning difficulties themselves so it was really it just didn't work. So finding a space for the children to have where they could get dressed in private, where they could have their own clothes because they were just picking dirty things up off the floor, coming to school wearing all sorts of different sort of things. (Key Worker I)

I've seen some things but never seen a house quite in that state. There was - it's not - it's overcrowded, it's too small for them to start with, but you couldn't walk across the floor in every single room. There's just clothes, food on the floor, empty packets... just looked as though somebody had gone in and ransacked the house and that's how they lived... there was no room for any drawers or anything, this was the problem, or wardrobes or anything. (Key Worker N)

It seems obvious that these properties are too small, that families need to move and should never have been given the property in the first instance, yet families seem to be powerless in influencing the decisions made by others about their housing arrangements. Two of the interviewees talked about previous experiences of homelessness and therefore fear of eviction remained ever present. Consequently, housing was often accepted by families at short notice, regardless of its unsuitability, because it was better than the alternative:

At the end of the day when my dad chucked us out that was the next house for the next weekend, so it was either get that or be homeless. (Mum, Family 40) 
p. 217. Domestic Surveillance and the Troubled Families Programme: Understanding relationality and constraint in the homes of multiply disadvantaged families

Although it might seem like a temporary measure when the property was accepted, it could be very difficult to move on due to waiting lists. This was exacerbated by problems with the tenancy, such as rent arrears or complaints about anti-social behaviour:

I want to move but they won't let me move because l've got rent arrears in the past because l've got an unsecured tenancy... Well l've been looking into private but they're going to want references from [housing provider] and then with all the anti-social behaviour they're going to tell them about ... (Mum, Family 34)

Sometimes parents delayed moving as children were now becoming settled within their school, and they didn't want to risk an upheaval at this time. This underlines the relational nature of decision making and personal agency within a family context, considering the impact of decisions on other family members.

All but one of the families interviewed lived in rented housing. The properties seemed to be of poor quality and often had a number of structural problems, particularly in relation to damp. Private landlords appeared reluctant to act to address these problems. This was incredibly demotivating since it seemed to families that there was little point trying to make the property nice with such problems persisting:

...the house that I moved out of was full of mould, so anything like that puts me down and I let the house go. So l've got another house now that's near enough going that way, but I'm trying to fight that... Since we had rain, along my settee, along my back wall it's all damp, and in my kitchen and in my boiler it's damp and electric points it's damp as well. So he said he'll do it, but he said he'll try and do it before the winter comes, but he said it was going to be a messy job. (Mum, Family 2)

\section{Poverty}

This highlights a third obstacle for families in maintaining the property to the standards expected by visiting services. For all families, money was tight, and even where they made their income meet the basic household needs of food, fuel etc, they could not make it stretch to home maintenance costs, yet housing providers failed to recognise this. One family home had been rewired by the housing provider, leaving damage to the plasterwork, coving and wallpapering, which the family could not afford to repair. One father told us how the gates and fencing had blown down in strong winds, but the housing provider claimed that it was not their responsibility to replace this. The family couldn't afford to re-fence, so were left exposed to thieves at the back of the house who stole a trailer with lawnmower and gardening equipment. They were subsequently warned by the landlord about the poor maintenance of the garden and need to mow the lawn, which the family now had no capacity to do.

Living a hand to mouth existence leaves little money over for replacing expensive household items. If something is stolen or breaks down, the family simply learn to live without it. In one family, where the dog had chewed the hoover, the 'house proud' mum was still trying to keep the carpets clean of dog hair by brushing them with a hand brush on her hands and knees, as she couldn't afford to replace the hoover. Several of the families lacked key items such as a hoover, cooker, fridge or washing machine. The lack of a washing machine was particularly felt in relation to the children's school attendance, since arriving at school in unwashed clothes led to bullying, and wearing the incorrect uniform could lead to detentions and exclusions. Key workers therefore supported families to acquire low cost second hand appliances or obtain external 
p. 218. Domestic Surveillance and the Troubled Families Programme: Understanding relationality and constraint in the homes of multiply disadvantaged families

funding. A father explained how his key worker had suggested he apply for a Community Care Grant to purchase a new freezer, but the complex regulations of such schemes made it difficult to navigate and led to delays in being able to replace essential items:

They turned me down. They said no, because apparently now whether you get the stuff or not you can only apply every 26 weeks... Even though you don't get it, you've still got to wait 26 weeks before you can apply again for it. Don't ask me how it works, I couldn't tell you. (Dad, Family 48)

Therefore where necessary these items were paid for out of the service budget. There were also examples of the key worker taking a hands-on approach to fixing household appliances.

We had to drag [the washing machine] out didn't we, try and fix the blooming thing ...flooded all my kitchen, didn't it. (Mum, Family 29)

\section{Oppressive relationships}

One final but significant obstacle faced by some families in maintaining the property is the existence of an abusive and controlling male partner in the home who does not contribute to household tasks, restricts the mother from cleaning or decorating the house, and controls spending on the home, as these women describe:

It's like I want it so different to how it is... and l'd just started redecorating my own way and [partner] comes back and he's just, like, "Oh we're not buying more paint, we're not doing this, we're not doing that," and it's, like, put me off, if you know what I mean. (Mum, Family 40)

Sometimes it was like, "Right we'd better get cleaned up in here" and he would be like, "No we're going to sit and watch a film" and it's like, "No I need to get cleaned up in here". "We're going to sit and watch a film and shut up and watch it". I should have just told him to get out. (Mum, Family 34)

These extreme behaviours reflect a wider lack of support within the home for daily household tasks. Of course it is not only in multiply disadvantaged families that women take responsibility for the bulk of the chores or complain about the lack of contribution from partners or children. Traditional assumptions about the gendered nature of housework as 'women's work' remain an obstacle to many families, with men avoiding responsibility for domestic and care work in the home (Tronto, 2013). Where some family members refuse to participate in new cleaning rotas, the burden usually falls to mothers to police the new regime or complete the tasks herself, as one mum describes:

I used to have a problem with him from the minute he used to wake up. I'd be asking "Why aren't you doing this, why aren't you doing this?" And now l'd just rather get on with it myself, if you know what I mean, and I can put it in perspective that he's not going to do it so l'll just do it, get on with it and it's just him out the way, sort of an easier life sort of thing. (Mum, Family 40)

Where expectations that the mother polices others' engagement with cleaning regimes escalates family conflict, this leaves mothers (and others in the household) vulnerable to further violence or aggression from partners or children. The decision by this mother to take on full responsibility for household chores in order to avoid conflict 
p. 219. Domestic Surveillance and the Troubled Families Programme: Understanding relationality and constraint in the homes of multiply disadvantaged families

may be seen as an exercise of agency, as a strategy for self-preservation within the context of her volatile and abusive relationship.

\section{Rethinking 'troubles' through relational autonomy}

The issue of the condition of the family home offers a particularly useful illustration of the complexity and interconnectedness of family problems, which provides an important critique of neoliberal attempts to recast social problems as personal failings. The distressing and sometimes inhumane conditions in which some families have found themselves can be seen to have diverse causes beyond the personal control and choices of the family members. Conversely the condition of the home also causes (or at the very least compounds) further problems for families.

There has been a growing recognition of the inadequacy and indeed the immorality of pursuing responsibilisation agendas within the TFP which emphasise human agency, autonomy and rational choice within the context of broader neoliberal politics that actually diminishes the power and autonomy of the most marginalised sections of society (Tew, 2013; Ball et al, 2016; Boddy et al, 2016; Bond-Taylor, forthcoming). Researchers have argued for the need to develop adequately theorised responses to the 'problem' which take into account context, constraint and relationality in respect of families facing multiple disadvantages (Jack and Gill, 2013; Flint, 2012), whilst keeping issues of agency at the fore (Parr, 2011). Theories of relational autonomy generated within a feminist ethics of care perspective offer a valuable alternative to neoliberal agendas, in that they conceptualise autonomy as situated in, and constituted by, relational contexts, both at the interpersonal and structural levels. The focus of neoliberalism on self-sufficiency and independence overlooks the relational interconnections which are fundamental to human life, and are particularly evident within 'families'. Theories of relational autonomy underpinned by the ethics of care have therefore been seen to unsettle responsibilisation agendas levied at 'troubled' families in a number of ways.

Firstly, by emphasising human interconnectedness over self-sufficiency, a relational perspective considers how we are bound by our commitment to the welfare of others. Decisions are not taken in a vacuum, but involve consideration of their impact on those around us and the constraints imposed by our relationship to others. Individual agency and action is guided by the social relations which matter most to the individual, embedded in structural and cultural contexts (Weaver and McNeill, 2015). Intensive family interventions can ameliorate some of these difficulties by considering the constraints of being part of a family unit and the impact of one person's actions on other family members, as well as supporting families to improve their frequently strained relationships with services, and advocating on behalf of families.

Secondly, relational autonomy acknowledges the elusivity of equality (Kittay, 1999), highlighting the different individual starting points which result from structural inequalities, and thereby challenging simplistic procedural accounts of autonomy over substantive accounts. Families within this research were frequently faced with a limited range of 'choices' none of which were clearly in their interests, and all of which were shaped by and further maintained their relative positions of powerlessness and material deprivation. These social positions, especially when combined with histories of abuse or other trauma, also restricted their imaginative repertoires (Mackenzie, 2000), and aspiration and future oriented thinking were minimal. Family problems are deeply rooted in the intersecting structural relations of society which may constitute a "matrix of domination' (Collins, 2000). Patriarchal and heteronormative power relations were particularly important in constituting families in this research, especially in the 
p. 220. Domestic Surveillance and the Troubled Families Programme: Understanding relationality and constraint in the homes of multiply disadvantaged families

interpersonal relations between men and women, and the traditional, working class gender division of parenting and domestic responsibilities. It is therefore unsurprising that in trying to change their lives, family members may demonstrate agency through their self-association with traditional gender roles as this enables them to forge positive identities through their relation to the gendered distribution of responsibilities for care.

Thirdly, relational perspectives emphasise the ways in which social contexts can generate or deny opportunities to develop or express autonomy and how conditions of oppression and domination disrupt the acquisition of autonomy competencies (McLeod and Sherwin, 2000). Families' experiences of difficult interactions with services must be taken seriously, since parents perceived by services as incompetent or irresponsible may find their autonomy undermined, and their voice and opportunities for selfdetermination denied. For a number of women in the research, this problem was exacerbated by their experiences of domestic abuse, in which their partner's violence was accompanied by controlling and belittling behaviour, preventing them from taking action to address issues in the home. The impact of oppressive interpersonal relationships is to severely undermine self-trust (McLeod and Sherwin, 2000) and for these women, this prompted a sense of worthlessness and incompetence which restricted their abilities to reflect upon the best course of action or see a way out of the nightmarish situation in which they found themselves. Personal agency within these contexts is extremely challenging and this can limit families' capacity to overcome the problems they face.

Finally, even where decisional autonomy is achieved, those living in marginalised or oppressed conditions may lack the skills or economic resources to affect their choices, or they may be constrained within relations of domination or coercion which prevent them acting. In the context of material deprivation, families often simply lacked the resources necessary to improve their lives and meet the demands of services, for example by replacing broken furniture or appliances, purchasing household cleaning equipment, or installing child safety gates. Families' economic vulnerability and precarity in the face of neoliberal economic policies and welfare reforms fundamentally underpinned their lives and shaped the problems they experienced and their interactions with others. It therefore also directed the exercise of personal agency by family members, whose choices and subsequent actions were inevitably restricted by the economic conditions they faced.

\section{Conclusions}

This article has explored interviews with families and key workers from a 'troubled' family intervention service to highlight the contextual and relational dimensions of the problems which families face. The focus has been on the condition of their domestic spaces because this acts as a trigger for referral and intervention, and because of the use of sanctions, incentives and conditionality in respect of this. Moreover, the political rhetoric and policy pronouncements around the TFP portray the 'troubled' family as irresponsible, anti-social and reluctant to respect the accepted standards of society, including around hygiene and cleanliness. This 'othering' pathologises and individualises family problems, and consequently paves the way for individual responsibilisation agendas rather than collective support and welfare for the vulnerable and excluded. Responsibilisation strategies which centre around the 'troubled' family home also tend to disproportionately target mothers, potentially reinforcing gendered divisions of domestic labour and caring responsibilities, and reproducing inequalities. 
p. 221. Domestic Surveillance and the Troubled Families Programme: Understanding relationality and constraint in the homes of multiply disadvantaged families

On the face of it, the focus of the TFP on domestic standards and maintaining the home may be interpreted as yet another example of the responsibilisation and domestication of working class women, with families introducing new cleaning regimes in the home so as to meet the exacting requirements of the various services. However, the key worker's role in this process is also seen by the families as empowering, through their attempt to tackle the social, economic and relational obstacles which prevent families (and mothers especially) from taking control of the domestic spaces they inhabit, and families can have very positive experiences of support. McLeod and Sherwin (2000: 260) have argued that 'the best way of responding to oppression's restrictive influence on an individual's ability to act autonomously is to change her life, not to try to make her adapt better to (or simply to manage to "overcome") those conditions privately'. In the context of this research, that included supporting women to end abusive relationships, accessing funds for urgent redecoration or the purchase of essential household items (such as beds, storage and white goods), and putting pressure on housing providers to find families more suitable accommodation or make long overdue repairs.

Considerations of relational autonomy therefore provide an important theoretical framework which considers the interplay between agency and structure, enhancing understanding of why it may be inappropriate, indeed unethical, for families with multiple disadvantages to be held wholly responsible for their choices, their actions or their inactions. Continuing to hold mothers to account for their failure to address the conditions within the home when they have no means of doing so exacerbates their feelings of powerlessness, and erodes self-worth and self-trust. Imposing sanctions or adopting assertive intervention styles in such contexts merely perpetuates the "cycle of injustice and distress' (Barnes, 2015: 41) which have come to characterise their lives, and fails to offer a way out of the cycle. Yet interventions with families do have the potential to provide a mechanism for developing relational autonomy by addressing conditions of domination and oppression, tackling material deprivation and working with families to enable family members to develop self-trust and autonomy skills through active collaboration in the process of family support. Family interventions can thereby be repositioned such that, rather than imposing an intrusive form of domestic surveillance levied at working class women, it may become as an opportunity to support families (and especially mothers) to overcome oppressive conditions which constrain personal agency.

\section{Acknowledgements}

I would like to thank the families and key workers who took part in the interviews for their valuable contributions, their openness and honesty. Thanks also to my doctoral supervisors Peter Somerville and Ana Jordan for their support in undertaking this research.

* Correspondence address: Sue Bond-Taylor, School of Social \& Political Sciences, University of Lincoln, Brayford Pool, Lincoln, LN6 7TS. Email: sbtaylor@lincoln.ac.uk 
p. 222. Domestic Surveillance and the Troubled Families Programme: Understanding relationality and constraint in the homes of multiply disadvantaged families

\section{References}

Ashe, F. (2014) 'All about Eve': Mothers, masculinities and the 2011 UK riots. Political Studies, 62, 3, 652-668.

Baier, A.C. (1987) The need for more than justice. Reprinted in: Held, V. (ed) (1995) Justice and care: Essential readings in feminist ethics. Oxford: Westview Press.

Ball, E., Batty, E. and Flint, J. (2016) Intensive Family Intervention and the Problem Figuration of 'Troubled Families'. Social Policy and Society, 15, 2, 263-274.

Barnes, M. (2012) Care in everyday life: An ethic of care in practice. Bristol: The Policy Press.

Barnes, M. (2015) Beyond the dyad: Exploring the multi-dimensionality of care. In: Barnes, M., Brannelly, T., Ward, L. and Ward, N. (eds) Ethics of care: Critical advances in international perspective. Bristol: Policy Press.

Boddy, J., Statham, J., Warwick, I., Hollingworth, K. and Spencer, G. (2016) What kind of trouble? Meeting the needs of 'troubled families' through intensive family support. Social Policy and Society, 15, 2, 275-288.

Bond-Taylor, S. (2014) The politics of 'anti-social' behaviour within the 'Troubled Families' Programme. In: Pickard, S. (ed) Anti-social behaviour in Britain: Victorian and contemporary perspectives. Basingstoke: Palgrave Macmillan.

Bond-Taylor, S. (2015) Dimensions of Family Empowerment in Work with so called 'Troubled' Families. Social Policy and Society, 14, 3, 371-384.

Bond-Taylor, S. (Forthcoming) Tracing an ethic of care in the policy and practice of the Troubled Families Programme. Social Policy \& Society.

Bond-Taylor, S. and Somerville, P. (2013) Evaluation of Families Working Together: Final report, Lincoln: University of Lincoln. Available at: http://eprints.lincoln.ac.uk/12527/ [Accessed: 21/04/2106].

Brown, A. (2004) Anti-social behaviour, crime control and social control. The Howard Journal, 43, 2, 203-211.

Christman, J. (2014) Relational autonomy and the social dynamics of paternalism. Ethical Theory and Moral Practice, 17, 3, 369-382.

Collins, P.H. (2000) Black feminist thought: Knowledge, consciousness, and the politics of empowerment, Second Edition. New York and London: Routledge.

Crossley, S. (2015a) Not 'dirty work', but 'the work that dirt does', Blog posted $2^{\text {nd }}$ April 2015. Available at: https://akindoftrouble.wordpress.com/2015/04/02/not-dirtywork-but-the-work-that-dirt-does/ [Accessed: 23/11/2015].

Crossley, S. (2015b) Realising the (troubled) family', 'crafting the neoliberal state. Families, Relationships and Societies, 5, 2, 263-279. DOI: http://dx.doi.org/10.1332/204674315X14326465757666.

De Benedictus, S. (2012) 'Feral' parents: Austerity parenting under neoliberalism. Studies in the Maternal, 4, 2, 1-21. DOI: http://doi.org/10.16995/sim.40

Department for Communities and Local Government (2012a) The Troubled Families Programme: Financial framework for the Troubled Families programme's payment-by-results scheme for local authorities, March 2012. London: DCLG. Available at: https://www.gov.uk/government/uploads/system/uploads/ attachment_data/file/11469/2117840.pdf [Accessed: 14/07/2014].

Department for Communities and Local Government (2012b) Working with Troubled Families: A guide to the evidence and good practice. December 2012. London: DCLG. Available at: https://www.gov.uk/government/uploads/system/uploads/attachment data/file /66113/121214_Working_with_troubled_families_FINAL_v2.pdf [Accessed: 20/07/2014].

Douglas, M. (1966) Purity and danger: An analysis of concepts of pollution and taboo. London: Routledge and Kegan Paul. 
p. 223. Domestic Surveillance and the Troubled Families Programme: Understanding relationality and constraint in the homes of multiply disadvantaged families

Fine, M. and Glendinning, C. (2005) Dependence, independence or inter-dependence? Revising the concepts of 'care' and 'dependency'. Aging and Society, 25, 4, 601 621.

Flint, J. (2012) The inspection house and neglected dynamics of governance: The case of domestic visits in Family Intervention Projects. Housing Studies, 27, 6, 822 838.

Garrett, P.M. (2007) 'Sinbin' solutions: the 'pioneer' projects for 'problem families' and the forgetfulness of social policy research. Critical Social Policy, 27, 2, 203-230.

Garrett, P.M. (2009) Transforming' children's services? Social work, neoliberalism and the 'modern' world. Maidenhead: Open University Press.

Gilligan, C. (1982) In a different voice: Psychological theory and women's development. Cambridge, MA, Harvard University Press.

Hayden, C. and Jenkins, C. (2014) 'Troubled families' programme in England: 'Wicked problems' and policy-based evidence. Policy Studies, 35(6): 631-649.

Jack, G. and Gill, O. (2013) Developing cultural competence for social work with families living in poverty. European Journal of Social Work, 16, 2, 220-234.

Kittay, E.F. (1999) Love's labor: Essays on women, equality and dependency. London and New York: Routledge.

Lawler, S. (2005) Disgusted subjects: The making of middle-class identities. The Sociological Review, 53, 3, 429-446.

Mackenzie, C. (2000) Imagining oneself otherwise. In: Mackenzie, C. and Stoljar, N. (eds) Relational autonomy: Feminist perspectives on autonomy, agency and the social self. New York and Oxford: Oxford University Press.

Mackenzie, C. and Stoljar, N. (2000) Introduction: Autonomy refigured. In: Mackenzie, C. and Stoljar, N. (eds) Relational autonomy: Feminist perspectives on autonomy, agency and the social self. New York and Oxford: Oxford University Press.

Macnicol, J. (1987) In pursuit of the underclass. Journal of Social Policy, 16, 3, 293318.

McLeod, C. and Sherwin, S. (2000) Relational autonomy, self-trust and health care for patients who are oppressed. In: Mackenzie, C. and Stoljar, N. (eds) Relational autonomy: Feminist perspectives on autonomy, agency and the social self. New York and Oxford: Oxford University Press.

Morris, K. (2012) Troubled Families: Vulnerable families' experiences of multiple service use. Child \& Family Social Work, 18, 2, 198-206.

Nixon, J. and Hunter, C. (2009) Disciplining women: Anti-social behaviour and the governance of conduct. In: Millie, A. (ed) Securing respect: Behavioural expectations and anti-social behaviour in the UK. Bristol: Policy Press.

Orwell, G. (1989) The Road to Wigan Pier. London: Penguin.

Parr, S. (2011a) Family policy and the governance of anti-social behaviour in the UK: Women's experiences of intensive family support. Journal of Social Policy, 40, 4, 717-737.

Parr, S. (2011b) Intensive family casework with 'problem' families: Past and present. Family Science, 2, 4, 240-249.

Parr, S. (2015) Integrating Critical Realist and Feminist Methodologies: Ethical and analytical dilemmas. International Journal of Social Research Methodology, 18, 2, 193-207.

Saugeres, L. (1999) The social construction of housing management discourse: Objectivity, rationality and everyday practice. Housing, Theory and Society, 16, 3, 93-105.

Skeggs, B. (1997) Formations of class and gender. London: Sage.

Starkey, P. (2000) The feckless mother: Women, poverty and social workers in wartime and post-war England. Women's History Review, 9, 3, 539-557.

Tew, J. (2013) Asset-based approaches and 'troubled families': Can the discourses join up? Families, Relationships and Societies, 2, 3, 467-470. 
p. 224. Domestic Surveillance and the Troubled Families Programme: Understanding relationality and constraint in the homes of multiply disadvantaged families

Tronto, J. (2013) Caring democracy: Markets, equality, and justice. New York and London: New York University Press.

Tyler, I. (2006) Chav scum: The filthy politics of social class in contemporary Britain. Media/Culture Journal, 9, 5. Available at: http://www.journal.mediaculture.org.au/0610/09-tyler.php [Accessed: 25/9/15].

Valentine, K. (2016) Complex needs and wicked problems: How social disadvantage became multiple. Social Policy and Society, 15, 2, 237-249.

Warner, J. (2015) The emotional politics of social work and child protection. Bristol: Policy Press.

Weaver, B. and McNeill, F. (2015) Lifelines: Desistance, social relations and reciprocity. Criminal Justice and Behavior, 42, 1, 95-107.

Welshman, J. (2012) 'Troubled families': The lessons of history, 1880-2012. History and Policy, $1^{\text {st }}$ October 2012. Available at: http://www.historyandpolicy.org/policypapers/papers/troubled-families-the-lessons-of-history-1880-2012 [Accessed: 21/04/2016]. 